\title{
ANALISIS DAMPAK EFEK BERGANDA PADA PANTAI SUWUK DI DESA TAMBAK MULYO KECAMATAN PURING KABUPATEN KEBUMEN
}

\author{
Indah Rohyani ${ }^{1}$, Dewi Noorsanti ${ }^{2}$, Siti Nur Azizah ${ }^{3}$ dan Sri Wahyuningsih ${ }^{4}$ \\ STIE Putra Bangsa Kebumen ${ }^{1,2,3}$ dan Politekknik Darma Patria Kebumen ${ }^{4}$ \\ Indahrohyani71@gmail.com ${ }^{l}$ dan yuni_delpipo@yahoo.co.id
}

\begin{abstract}
Suwuk Beach is one of the leading coastal tourism destinations in Kebumen Regency. In 2018 Suwuk beach is still an attractive destination for tourists with 287,085 tourists. This can bring economic benefits to the people in the Suwuk coastal area. To determine the impact of the economy, the researchers used a multiplier effect formula. The results found in this study are the multipliyer's effect on type I and II, namely Multiplier Effect 2.44, Keynesian Local Income Multiplier 1.2 and Ratio Income Multiplier of 1.6 so that tourism activities have an economic impact on people's income.
\end{abstract}

Key Word : Economic Impact, Multiplier Effect, Keynesian Local Income Multiplier, Ratio Income Multiplier

\section{Abstrak}

Pantai Suwuk merupakan salah satu unggulan wisata pantai di Kabupaten Kebumen. Pada tahun 2018 pantai Suwuk masih menjadi tujuan wisatan yang menarik dengan jumlah wisatawan 287.085. Hal tersebut bisa mendatangkan keuntungan ekonomi bagi masyarakat di lingkungan pantai Suwuk.Untuk mengetahui dampak perekonomian maka peneliti menggunakan formula multiplier effect. Hasil yang ditemukan dalam penelitian ini adalah adanya efek multipliyer baik pada tipe I maupun II yaitu Multiplier Effect 2.44, Keynesian Local Income Multiplier 1,2 dan Ratio Income Multiplier sebesar 1,6 sehingga kegiatan pariwisata memberikan dampak ekonomi pada pendapatan masyarakat

Kata Kunci : Dampak ekonomi, Multiplier Effect, Keynesian Local Income Multiplier, Ratio Income Multiplier

\section{A. PENDAHULUAN}

Pantai Suwuk merupakan salah satu unggulan wisata pantai di Kabupaten Kebumen. Selama beberapa periode perkembangan jumlah kunjungan wisatawan di Pantai Suwuk Kebumen terus mengalami peningkatan. Hal ini menunjukan bahwa Pantai Suwuk Kebumen memiliki potensi untuk terus berkembang dan berperan pada peningkatan pendapatan masyarakat sekitar kawasan wisata tersebut. Berikut tabel kunjungan wisatawan pantai Suwuk Kebumen:

Tabel 1. Jumlah Pengunjung Pantai Suwuk

\begin{tabular}{|c|c|c|}
\hline No. & Tahun & Jumlah Pengunjung \\
\hline 1 & 2013 & 227.350 \\
\hline 2 & 2014 & 340.637 \\
\hline 3 & 2015 & 454.642 \\
\hline 4 & 2016 & 362.190 \\
\hline 5 & 2017 & 246.100 \\
\hline 6 & 2018 & 287.085 \\
\hline \multicolumn{2}{|c|}{ Jumlah } & 1.384 .819 \\
\hline
\end{tabular}

Sumber : Kebumen Dalam Angka, BPS 2013-2017

Berdasarkan tabel diatas, jelas bahwa pada setiap tahun jumlah pengunjung selalu meningkat, hal tersebut sangat berdampak pada peningkatan pendapatan masyarakat sekitar pantai Suwuk 
Kebumen. Seperti pendapat dari Wan Chai (2009:91) yang menyatakan bahwa "Jumlah pendapatan akan meningkat pesat, apabila pengeluaran wisatawan di daerah tujuan wisata juga meningkat". Supaya pendapatan masyarakat sekitar pantai Suwuk terus mengalami peningkatan, maka perlu adanya pengembangan pariwisata yang lebih menunjang para wisatawan.

Adapun pada tahun 2018 pantai Suwuk mengalami penurunan pengunjung karena akibat adanya gelombang tinggi pada bulan Juli 2018, sehingga banyak fasilitas pariwisata seperti baik itu warung permanen maupun tidak permanen, paving dan tumbuh-tumbuhan disekitar rusak. Hal tersebut bisa berdampak terhadap kunjungan wisatawan ke pantai Suwuk untuk ke depannya. Untuk itu pihak manajemen pantai Suwuk segera melakukan perbaikan dan pengembangan di lokasi sekitar pantai agar pengunjung bisa datang kembali untuk berwisata.

Pengembangan pariwisata berkelanjutan adalah sebuah aktivitas melaksanakan perjalanan yang bertujuan untuk memperoleh kenikmatan, kenyamanan, mencari sesuatu, memperbaiki kesehatan, menikmati olahraga atau istirahat (Meyer, 2009). Sedangkan menurut E. Geyer Feuler pariwisata adalah gabungan gejala dan hubungan yang timbul dari interaksi wisatawan, pelaku bisnis, pemerintah tuan rumah serta masyarakat tuan rumah dalam proses menarik dan melayani wisatawan dan pengunjung. Pemerintah memiliki peran dalam mengatur kedatangan dan kepulangan wisatawan.Swasta berperan menyediakan hotel, restoran, tempat karaoke, wahana permainan untuk anak-anak maupun dewasa dan sebagainya. Sedangkan masyarakat memiliki peran sebagai penunjuk jalan dan menyediakan souvenir (Soekadijo, 1997:8).

Analisis dampak ekonomi pariwisata terhadap masyarakat sekitar telah dilakukan beberapa kali oleh peneliti-peneliti sebelumnya. Penelitian M Ihsan (2017) mengenai multiplier effect industri pariwisata Candi Muara Takus terhadap perekonomian masyarakat hasilnya menunjukkan persepsi pengunjung $54 \%$ cukup baik, persepsi bisnis $65 \%$ dan persepsi tenaga kerja $66 \%$ baik. Alat penilaiannya menggunakan Keynesian, hasilnya menunjukkan income multiplier ratio tipe I dengan nilai 1, tipe ratio penghasilan II penggandanya 1,19 sesuai dengan ketentuan. Hasilnya lebih besar dari 1 artinya memiliki dampak terhadap ekonomi. Ariyanti (2014) mengenai pengaruh sektor pariwasata terhadap perekonomian Bukittinggi dengan analisa input output. Hasilnya menunjukkan pengaruh multiplier ratio lebih dari satu untuk sektor perdagangan dan eceran dan pengangkutan.

Penelitian yang dilakukan oleh Nugraheni (2013) mengenai strategi pengembangan pantai Suwuk ditinjau dari segi pengeloaan pemasaran, hasilnya menunjukkan $61 \%$ responden resonden menyatakan pengelolaan pantai Suwuk sudah baik $7 \%$ menyatakan ada kekurangan. Keterlibatan pemerintah $59 \%$ menyatakan sudah baik, $37 \%$ menyatakan pemerintah belum mengelola dengan baik. Kekurangnnya adalah sarana prasarana yang belum maksimal terutama persampahan. Analisa yang dipakai adalah deskriktif kuantitatif.

Penelitian yang dilakukan oleh Sri Ubanti (2015) mengenai pengukuran kontribusi terhadap nilai obyek wisata kawasan Rawapening pendekatan multiplier efek. Hasilnya menunjukkan sektor jasa lebih besar dalam memberikan dampak dibanding sektor lainnya seperti pertanian dan perdagangan.

Dari beberapa penelitian yang sudah dilakukan sebelumnya seperti pada penelitian terdahulu yang sudah dijelaskan secara singkat, maka dapat dilihat aspek, metode serta pendekatanyang digunakan dalam penelitian tersebut. Pada penelitian ini, aspeknya adalah mengenai dampak ekonomi dari kegiatan wisata yang terjadi di Pantai Suwuk. Metode yang digunakan dalam penelitian ini adalah analisis deskriptif dan analisis dampak berganda (multiplier effect). Selain itu, terdapat satu aspek yang membedakan penelitian ini dengan penelitian terdahulu yaitu pada penelitian ini juga dikaji mengenai aspek persepsi responden dalam pengelolaan wisata Pantai Suwuk sehingga dapat dijadikan referensi untuk mengadakan perbaikan dari kondisi yang terbaru saat ini.

Analisis pada penelitian ini adalah karakteristik dari pengunjung, dan pelaku pengelolaan wisata di Pantai Suwuk. Seperti usia dan tingkat pendidikan terakhir, responden yang memiliki pendidikan yang lebih tinggi akan lebih objektif dalam menilai atau memberikan persepsi terhadap pengelolaan wisata. Dengan adanya penilaian atau persepsi dari pengunjung maka dapat menjadi informasi penting bagi pengelola untuk terus melakukan perbaikan terhadap sarana dan prasarana guna meningkatkan pengembangan dan pengelolaan wisata dikawasan tersebut. Kegiatan wisata di Pantai Suwuk diduga memberi manfaat ekonomi yang sangat baik terutama untuk masyarakat yang memiliki mata pencaharian terkait dengan kegiatan wisata.

Terjadi perubahan pada pengelolaan Pantai Suwuk pada tahun 2018 yaitu akibat terjadinya gelombang pasang (tsunami kecil) yang mengakibatkan kerusakan fasilitas wisata meliputi robohnya menara, kios dan warung makan, mini zoo kecil dan kolam renang anak-anak. Sehingga berpengaruh terhadap kunjungan wisatawan sebanyak $68 \%$ dan tidak beroperasionalnya beberapa usaha warung 
karena rusak serta menurunnya keindahan dan kenyamanan di sekitar pantai. Hal ini berdampak langsung pada turunnya pendapatan pedagang dari penurunan jumlah kujungan tersebut.

\section{B. METODE PENELITIAN}

Penelitian ini dilakukan di Pantai Suwuk terletak di Desa Tambakmulyo, Kecamatan Puring, Kabupaten Kebumen. Pemilihan lokasi dilakukan secara sengaja (purposive), dengan pertimbangan bahwa wisata di Pantai Suwuk memiliki banyak potensi yang dapat dikembangkan menjadi salah satu kawasan wisata andalan. Pengambilan data lapangan dilakukan pada bulan Januari - Februari 2019. Jenis data yang dikumpulkan dalam penelitian ini meliputi data primer dan data sekunder, baik secara kuantitatif maupun kualitatif. Pengumpulan data primer akan dilakukan dengan teknik survey yakni mengumpulkan data dengan mengajukan pertanyaan baik lisan maupun tertulis dengan menggunakan kuesioner kepada pengunjung dan wawancara dengan unit usaha lokal, dan tenaga kerja, dan pengunjung (wisatawan) yang terlibat dalam kegiatan wisata. Data sekunder yang diperlukan dalam penelitian ini merupakan data pendukung yang akan diambil dari berbagai instansi, studi literatur atau referensi lainnya (jurnal, buku, artikel hasil penelitian sebelumnya, dan penelusuran melalui internet) yang terkait dengan lingkup permasalahan penelitian. Ukuran sampel sebanyak 380 responden. Berdasarkan hasil survey yang telah dilakukan, maka data yang di dapatkan dari instansi terkait dan observasi lapangan diobjek wisata Pantai Suwuk dikunjungi oleh rata-rata 1330 per hari pada saat musim liburan dan hari raya Idul Fitri. Karena jumlah populasi tidak menentu maka penentuan sampel menggunakan convinience sampling dimana setiap anggota polulasi dapat menjadi sampel dan digunakan rumus Solvin sebagai berikut:

$$
\mathrm{N}=\frac{\mathrm{N}}{\left(1+\left(\mathrm{N} \times \mathrm{e}^{2}\right)\right)}
$$

Keterangan:

$\mathrm{N}=$ ukuran sampel/Jumlah Respoden

$\mathrm{e}=$ prosentase kelonggaran ketelitian kesalahan sampel yang masih bisa ditolerir, $\mathrm{e}=5 \%$

Hasil perhitungan sampel adalah sebagai berikut :

$\begin{array}{ll}\mathbf{N} & =\frac{1330}{\left(1+\left(1330 \times 0,05^{2}\right)\right)} \\ & =\frac{1330}{(1+2,5)} \\ & \\ N & =330\end{array}$

Jadi jumlah sampel wisatawan yang diambil dari pengunjung adalah 380 orang.

Dari hasil observasi lapangan yang telah dilakukan, dapat diketahui bahwa unit usaha yang terdapat disekitar objek wisata Pantai Suwuk berjumlah 120 unit kios yang sebagian besar adalah warung makan. Maka jumlah sampel diambil $30 \%$ dari populasi 36 pedagang kios. Pedagang asongan sekitar 50 unit, jumlah sampel diambil $10 \%$ sejumlah 5 unit.1 unit penginapan sehingga merupakan sampel sekaligus populasi. Maka populasi unit usaha yang terdapat disekitar lokasi pantai Suwuk Kebumen adalah 42 unit.

Dari hasil observasi dilapangan jumlah populasi tenaga kerja yang bekerja pada unit usaha yang terdapat disekitar kawasan wisata Pantai Suwuk sebanyak 120 orang. Penentuan sampel responden pada tenaga kerja dikawasan wisata Pantai Suwuk Kebumen dilakukan dengan bentuk purposive sampling, dimana anggota responden akan dipilih dan disesuaikan dengan kriteria tertentu berdasarkan keterwakilan jenis usaha. Jumlah responden untuk tenaga kerja adalah sebanyak 20 orang, dan 4 orang untuk jenis usaha penginapan.

Analisis data bertujuan untuk menyederhanakan data ke dalam bentuk yang lebih mudah dipahami dan diinterpretasikan. Data yang akan dicari kemudian dikumpulkan dan selanjutnya akan dianalisis secara deskriptif dan disajikan dalam bentuk tabel, gambar atau grafik serta perhitungan matematik. 
Dalam penelitian ini data yang dikumpulkan akan diolah dengan aplikasi komputer, seperti Microsoft Excel 2007.Metode analisis data yang akan digunakan dalam penelitian ini terdiri atas dua metode yaitu analisis deskriptif dan analisis dampak berganda (multiplier effect).

Tabel 2. Matriks Metode Analisis Data

Tujuan Penelitian

Jenis dan Sumber Data

Metode Analisis

Mengidentifikasi
pengunjung, pelaku usaha, tenaga
kerja, dan pengelola (stakeholder)
disekitar Pantai Suwuk
Mengidentifikasi persepsi pengunjung,
pelaku usaha, tenaga kerj tentang
wisata pantai Suwuk
Menganalisis dampak kegiatan wisata
di Pantai suwuk kebumen terhadap
perekonomian masyarakat setempat.

Data primer dengan
wawancara menggunakan
kuesioner.

Analisis deskriptif

Data primer dengan Analisis deskriptif wawancara menggunakan kuesioner

Data primer dengan wawancara menggunakan kuesioner
Efekmultiplier (keynesian income multiplier, Ratioincome multiplier

\section{Analisis Deskriptif}

Metode deskriptif adalah suatu metode dalam meneliti status sekelompok manusia, suatu objek, suatu kondisi, suatu sistem pemikiran ataupun suatu kelas peristiwa pada masa sekarang.

\section{a. Karakteristik Pengunjung, Pelaku Usaha, Tenaga Kerja, dan Pengelola (stakeholder)}

Karakteristik pengunjung, pelaku usaha, tenaga kerja perlu di identifikasi untuk mengetahui bagaimana tren yang terdapat pada kegiatan wisata alam di Pantai Suwuk. Untuk mengidentifikasi karakteristik pelaku usaha, indikator atau parameter yang digunakan adalah umur, jenis kelamin, pendidikan terakhir, pendapatan, dan lama berusaha.

1. Karakteristik Pengunjung $(\mathrm{N}=380)$

Tabel.3 Karateristik Pengunjung

\begin{tabular}{|c|c|c|}
\hline Karakteristik responden & Prosentase & Jumlah \\
\hline \multicolumn{3}{|l|}{ Jenis Kelamin } \\
\hline - $\quad$ Laki laki & 43 & 164 \\
\hline - $\quad$ Perempuan & 57 & 216 \\
\hline \multicolumn{3}{|l|}{ Umur } \\
\hline $17-25$ & 35 & 133 \\
\hline $26-35$ & 37 & 140 \\
\hline $36-45$ & 17 & 65 \\
\hline$-\quad>46$ & 11 & 42 \\
\hline \multicolumn{3}{|l|}{ Pendidikan } \\
\hline$-\quad \mathrm{SD}$ & 12,89 & 49 \\
\hline SMP & 23,94 & 91 \\
\hline SMA & 37,89 & 144 \\
\hline Diploma & 19,73 & 75 \\
\hline Sarjana & 5,55 & 21 \\
\hline
\end{tabular}




\begin{tabular}{|c|c|c|}
\hline$<1$ juta rupiah & 36 & 136 \\
\hline 1 juta $-2,5$ juta rupiah & 33 & 127 \\
\hline 2,6 juta -5 juta rupiah & 14 & 54 \\
\hline$>5$ juta rupiah & 17 & 63 \\
\hline
\end{tabular}

Sumber: data primer diolah, 2019

2. Karakteristik Pelaku Usaha $(\mathrm{N}=42)$

Tabel 4. Karateristik Pelaku Usaha

\begin{tabular}{|c|c|c|}
\hline Karakteristik responden & Prosentase & Jumlah \\
\hline \multicolumn{3}{|l|}{ Jenis Kelamin } \\
\hline - $\quad$ Laki laki & 52,38 & 22 \\
\hline Perempuan & 47,62 & 20 \\
\hline \multicolumn{3}{|l|}{ Umur } \\
\hline $17-25$ & 10 & 4 \\
\hline $26-35$ & 52 & 22 \\
\hline $36-45$ & 24 & 10 \\
\hline$>46$ & 14 & 6 \\
\hline \multicolumn{3}{|l|}{ Pendidikan } \\
\hline SD & 38,1 & 16 \\
\hline SMP & 40,48 & 17 \\
\hline SMA & 21,42 & 9 \\
\hline \multicolumn{3}{|l|}{ Pendapatan } \\
\hline$<2$ juta rupiah & 26 & 11 \\
\hline 2,1 juta -3 juta rupiah & 33 & 14 \\
\hline 3.1 juta -5 juta rupiah & 31 & 13 \\
\hline$>5$ juta rupiah & 10 & 4 \\
\hline \multicolumn{3}{|l|}{ Lama usaha } \\
\hline 1 th & 19 & 8 \\
\hline $2-4$ th & 43 & 18 \\
\hline $5-7$ th & 26 & 11 \\
\hline$<7$ th & 12 & 5 \\
\hline
\end{tabular}

Sumber: data primer diolah, 2019

3. Karakteristik Tenaga kerja $(\mathrm{N}=24)$

Tabel 5. Karateristik Tenaga Kerja

\begin{tabular}{|l|c|c|}
\hline Karakteristik responden & Prosentase & Jumlah \\
\hline Jenis Kelamin & & 16 \\
$-\quad$ Laki laki & 67 & 8 \\
\hline$\quad$ Perempuan & 33 & 9 \\
\hline Umur & 38 & \\
\hline
\end{tabular}




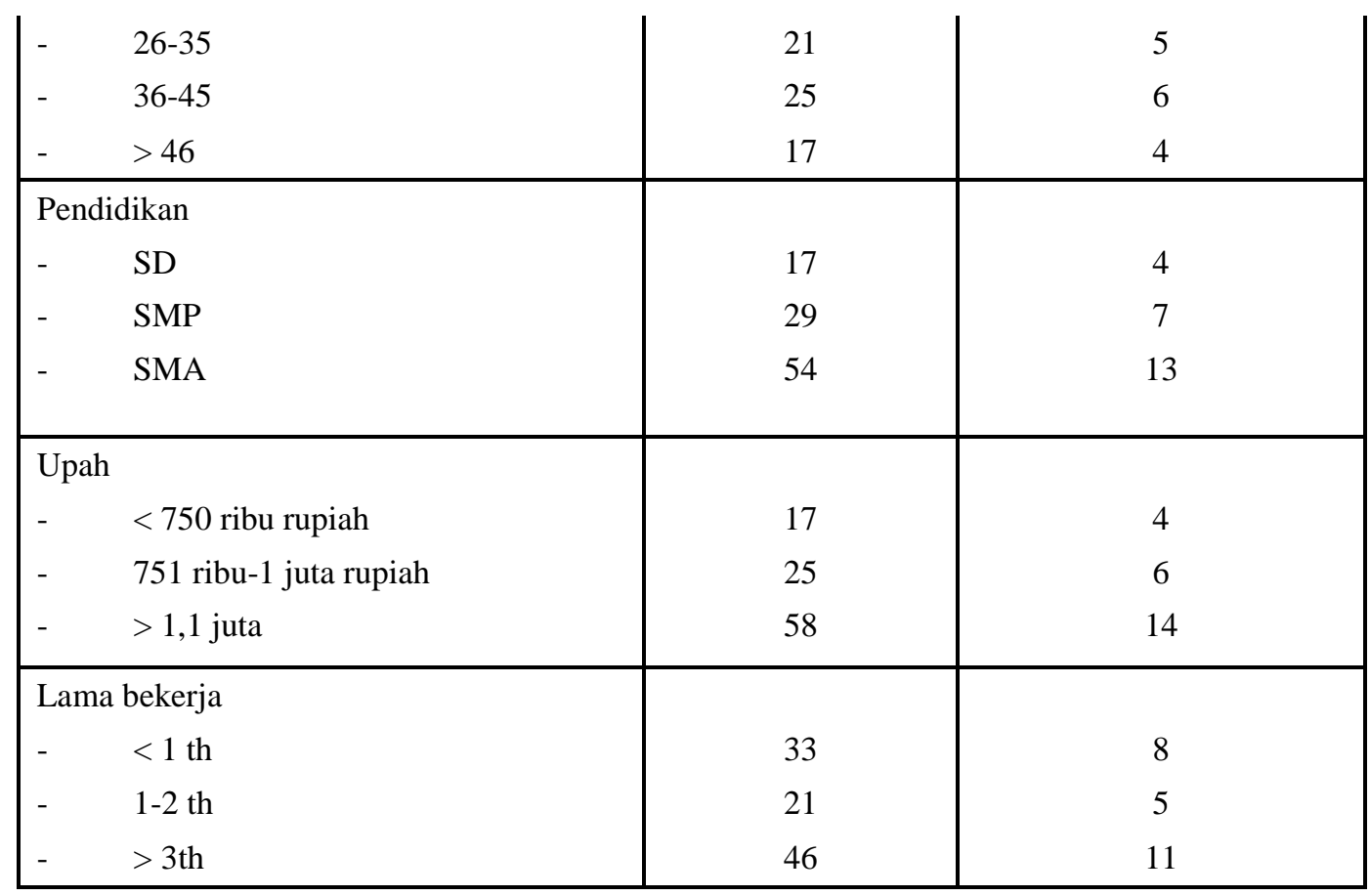

Sumber: data primer diolah, 2019

\section{b. Analisis Dampak Berganda (Multiplier Effect Analysis)}

Dampak ekonomi ini dapat diukur dengan menggunakan efek pengganda atau multipli er effect dari arus uang yang terjadi. Dalam mengukur dampak ekonomi kegiatan pariwisata ditingkat lokal, terdapat dua tipe pengganda,yaitu:

1. Keynesian Local Income Multiplier, yaitu nilai yang menunjukkan berapa besarpengeluaranpengunjung berdampakpadapeningkatanpendapatan masyarakat lokal.

2. Ratio Income Multiplier, yaitu nilai yang menunjukkan seberapa besar dampaklangsungyangdirasakandaripengeluaranpengunjung berdampak padakeseluruhanekonomilokal. Penggandainimengukurdampaktidak langsungdan dampak induced.

Secaramatematis dirumuskan :

Keynesian Income Multiplier

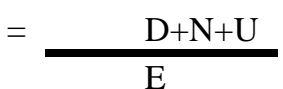

Rasio Income Multiplier, Tipe I

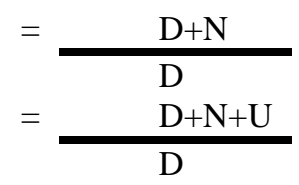

Rasio Income Multiplier, Tipe II

$\mathrm{D}$

dimana:

E : pengeluaran pengunjung(Rupiah)

$\mathrm{D}$ : pendapatan lokalyangdiperoleh secaralangsungdari E (Rupiah)

$\mathrm{N}$ : pendapatan lokalyangdiperoleh secaratidak langsungdari E (Rupiah)

$\mathrm{U}$ : pendapatan lokalyangdiperoleh secarainduced dari E (Rupiah)

Impact dari kegiatan wisata dapat diestimasi. Selanjutnya informasi ini dapat digunakan untuk mengidentifikasi dampak ekonomi kegiatan pariwisata pantai Suwuk terhadap pendapatan masyarakat,dan manfaat apa yang akan diterima oleh masyarakat.

\section{HASIL DAN PEMBAHASAN}

\section{a. Lokasi Pantai Suwuk}

Pantai Suwuk merupakan kawasan wisata yang terletak di Kabupaten Kebumen sebelah 
selatan, tepatnya di Dusun Suwuk, Desa Tambakmulyo, Kecamatan Puring, Kabupaten Kebumen. Lebih tepatnya, Pantai Suwuk terletak $22 \mathrm{~km}$ sebelah selatan Gombong, $35 \mathrm{~km}$ sebelah barat daya Karanganyar dan $50 \mathrm{~km}$ dari Kota Kebumen. Keistimewaan Pantai Suwuk ini dikarenakan oleh letaknya yang berdekatan dengan pegunungan Karangbolong dan sungai Telomoyo yang merupakan sungai terbesar di Kabupaten Kebumen. Bibir pantai di Pantai Suwuk ini tergolong cukup curam dengan kemiringan 35 derajat

\section{b. Multiplier Effect}

Nilai Multiplier ekonomi merupakan nilai yang menunjukkan sejauh mana pengeluaran wisatawan akan menstimulasi pengeluaran lebih lanjut, sehingga pada akhirnya meningkatkan aktivitas ekonomi ditingkat local. Untuk itu, hasil yang diperoleh dari penelitian ini adalah pantai Suwuk memiliki dampak ekonomi kepada masyarakat sekitar, karena nilai multipliernya $>1$. Kegiatan pariwisata di Pantai Suwuk tidak terlepas dari fasilitas-fasilitas yang menunjang kegiatan pariwisata tersebut. Pantai Suwuk pun memiliki fasilitas-fasilitas wisata berupa rumah makan dan hotel/penginapan.

Tabel 6. Fasilitas di Pantai Suwuk

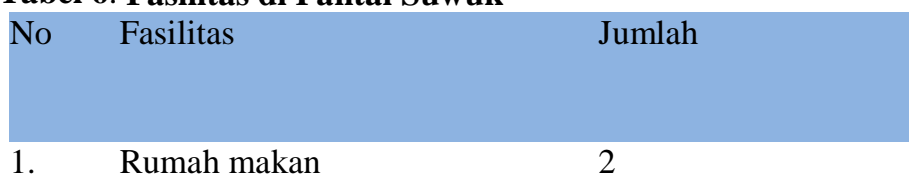

2. Hotel atau Penginapan $\quad 1$

Sumber: Olahan Data Peneliti, 2019

Jumlah rumah makan yang terbatas tersebut mampu memenuhi kebutuhan wisatawan dikarenakan banyak tersedia juga kios makanan yang menjual makanan khas Pantai Suwuk. Selain itu, penginapan yang baru berjumlah 1 unit tersebut memang masih tergolong baru dan mampu menjadi fasilitas pendukung kegiatan pariwisata di Pantai Suwuk.

\section{c. Rata-Rata Pengeluaran Wisatawan}

Untuk mendapatkan rata-rata pengeluaran wisatawan, peneliti menggunakan teknik penyebaran kuesioner kepada wisatawan yang mengunjungi Pantai Suwuk. Responden dalam penelitian ini adalah wisatawan lokal mengingat mayoritas wisatawan yang mengunjungi Pantai Suwuk adalah wisatawan lokal. Peneliti melakukan penyebaran kuesioner kepada 380 responden yang tersebar di Pantai Suwuk. Hasil penyebaran kuesioner adalah sebagai berikut:

Tabel 7. Pengeluaran pengunjung:

\begin{tabular}{|l|l|c|}
\hline \multicolumn{1}{|c|}{ Biaya } & \multicolumn{1}{|c|}{ Pengeluaran } & Prosentase \\
\hline Penginapan & 20.000 .000 & 0,32 \\
\hline Makan minum & 20.050 .000 & 0,33 \\
\hline Parkir & 1.038 .000 & 0,02 \\
\hline Tiket & 6.075 .000 & 0,11 \\
\hline Kolam renang & 2.040 .000 & 0,03 \\
\hline Sewa motor/kuda & 1.070 .000 & 0,02 \\
\hline Sewa perahu & 1.000 .000 & 0,01 \\
\hline Sovenir & 5.085 .000 & 0,09 \\
\hline Bensin & 20.088 .000 & 0,34 \\
\hline Total & 61.500 .000 & $100 \%$ \\
\hline
\end{tabular}

Sumber: Olahan data peneliti, 2019 
Dalam Tabel diatas dapat dilihat bahwa presentase pengeluaran wisatawan paling besar yaitu bensin. $(34 \%)$ sedangkan yang terkecil sewa perahu (1\%). Selain itu, dalam menghitung ratarata pengeluaran wisatawan, peneliti menggunakan perhitungan $\mathrm{AC}=\mathrm{TC} / \mathrm{Q}$. Rumusnya adalah sebagai berikut:

Average tourist spending $=$ Jumlah pengeluaran wisatawan/jumlah sampel wisatawan $=61.500 .000 . / 380$

$=\mathbf{1 6 1 . 8 4 2}$

Hasil penelitian menunjukkan rata-rata pengeluaran wisatawan untuk satu kali kunjungan yaitu Rp.161.842 untuk setiap kali kunjungan.

\section{d. Income Generation}

Analisis Income generation akan dihitung menggunakan rumus keynesian income multiplier yang disampaikan oleh (META:2001) untuk mendapatkan besarnya multiplier effect dari adanya pengeluaran wisatawan di Pantai Suwuk. Rumus keynesian multiplier ini akan mencari masing-masing pembentuk pendapatan langsung, pembentuk pendapatan tidak langsung, dan pembentuk pendapatan tambahan sehingga nilai dari multiplier effect dapat diketahui. Berikut adalah rumus menghitung income multiplier:
Dimana :
$\mathrm{D}=$ Pendapatan
$\mathrm{N}=$ Pendapatan
$\mathrm{U}=$ Pendapatan
$\mathrm{E} \quad=$ Pengeluaran pengunjung

Keynesian Income Multiplier: $\frac{D+N+U}{E}$

e. Total Pendapatan Pelaku Usaha

Berdasarkan wawancara yang dilakukan bersama pelaku usaha, maka diperoleh pendapatan sebagai berikut:

Tabel 8. Tota Pendapatan Pelaku Usaha

\begin{tabular}{|l|c|}
\hline \multicolumn{1}{|c|}{ Unit usaha } & Total pendapatan pemilik/bulan (Rp) \\
\hline Kios & 50.100 .000 \\
\hline Penginapan & 9.600 .000 \\
\hline Rumah makan & 16.600 .000 \\
\hline Souvenir & 7.900 .000 \\
\hline Penyewaan kuda tunggang & 3.170 .000 \\
\hline Penyewaan Perahu & 6.450 .000 \\
\hline Total & 93.820 .000 \\
\hline
\end{tabular}

Sumber: olahan data peneliti, 2019

Dari tabel diatas dapat dilihat bahwa jumlah pendapatan yang paling besar adalah Rp.50.100.000,- yaitu pendapatan dari pemilik kios dengan sampel sejumlah 36 orang.

\section{f. Indirect Income Generation}

Indirect income generation menurut Archer (1976:115) merupakan pengeluaran yang disebabkan oleh adanya pembayaran gaji dan upah kepada karyawan lokal atau perusahaan wisata untuk mengisi saham mereka. Dampak ekonomi tidak langsung dapat dilihat dari proporsi upah karyawan terhadap pendapatan pelaku usaha. Berdasarkan wawancara terhadap tenaga kerja lokal disekitar pantai Suwuk didapatkan data rata-rata pendapatan tenaga kerja perbulan dapat dilihat dalam tabel berikut ini: 
Tabel 9. Total Pendapatan Tenaga Kerja Lokal

\begin{tabular}{|l|c|}
\hline \multicolumn{1}{|c|}{ Unit usaha } & Total pendapatan tenaga kerja local (Rp/bulan) \\
\hline Kios & 5.600 .000 \\
\hline Penyewaan Perahu & 1.000 .000 \\
\hline Rumah makan & 8.000 .000 \\
\hline Penginapan & 5.150 .000 \\
\hline Total & 19.750 .000 \\
\hline
\end{tabular}

Sumber: olahan data peneliti, 2019

Jumlah pendapatan yang paling tinggi adalah penjaga penginapan sebesar Rp.5.150.000,dengan jumlah tenaga kerja sebanyak 4 orang. Total pendapatan paling kecil adalah penjaga kios sebesar Rp.5.600.000,- dengan jumlah karyawan sebanyak 15 orang. Pendapatan tenaga kerja di Kios memiliki pendapatan yang paling kecil dikarenakan hari kerjanya hanya 2 kali perminggu.

\section{g. Multiplier Effect}

Berdasarkan perhitungan rumus diperoleh nilai arus uang (efek berganda). Berikut tabel nilai efek berganda dari arus uang di pantai Suwuk terhadap pendapatan masyarakat :

Tabel 9. Nilai Multiplier Arus Uang

\begin{tabular}{|l|c|}
\hline \multicolumn{1}{|c|}{ Kriteria } & Nilai Multiplier \\
\hline Keynesian Local Income Multiplier & 2,44 \\
\hline Ratio Income Multiplier Type 1 & 1,21 \\
\hline Ratio Income Multiplier Type 2 & 1,60 \\
\hline
\end{tabular}

Sumber: Hasil olahan peneliti, 2019

Penjelasan dari tabel 9, menunjukkan bahwa nilai Keynesian Local Income Multiplier di pantai Suwuk sebesar 2,44 artinya bahwa setiap pengeluaran wisatawan sebesar Rp.100.000,- akan berdampak pada pendapatan masyarakat local sebesar Rp. 244.000,-. Pada Ratio Income Multiplier Type 1, menunjukkan nilai sebesar 1,21 yang berarti setiap pendapatan unit usaha yang berasal dari pengeluaran wisatawan akan mempengaruhi pendapatan sebesar Rp. 121.000,-, terutama pada total pendapatan masyarakat yang berupa dampak langsung maupun tidak langsung (berupa pendapatan pemilik usaha dan tenaga kerja local). Sedangkan pada Ratio Income Multiplier Type II, menunjukkan hasil 1,60 yang berarti setiap Rp. 100.000,- dari pengeluaran wisatawan akan mengakibatkan pendapatan pemilik unit usaha sebesar Rp. 160.000,- pada total pendapatan masyarakat yang meliputi dampak langsung, tidak langsung dan induced (berupa pendapatan pemilik unit usaha, pendapatan tenaga kerja local dan pengeluaran untuk konsumsi di tingkat local). Dari hasil tersebut dapat di simpulkan bahwa pantai Suwuk memberikan dampak ekonomi yang cukup baik kepada masyarakat, karena memiliki nilai multiplier lebih dari 1 . Hal tersebut telah dijelaskan oleh META (2001) yang mengatakan bahwa bila nilai Keynesian Income Multiplier > 1, maka aktivitas wisata di kawasan pantai Suwuk memiliki dampak ekonomi yang besar bagi masyarakat lokal.

\section{h. Persepsi Sarana Prasarana}

Dibawah ini data persepsi pengunjung terhadap sarana prasarana sebagai berikut:

Tabel 10. Persepsi Pengunjung (prosentase)

\begin{tabular}{|l|l|l|l|l|}
\hline & Baik & Cukup & Kurang & Buruk \\
\hline
\end{tabular}




\begin{tabular}{|l|l|l|l|l|}
\hline Panorama & $0 \%$ & $100 \%$ & $0 \%$ & $0 \%$ \\
\hline Kemananan & $100 \%$ & $0 \%$ & $0 \%$ & $0 \%$ \\
\hline Sarpras & $0 \%$ & $92 \%$ & $8 \%$ & $0 \%$ \\
\hline Kelengkapan Bermain & $0 \%$ & $89 \%$ & $11 \%$ & $0 \%$ \\
\hline Pengelolaan sampah & $0 \%$ & $0 \%$ & $100 \%$ & $0 \%$ \\
\hline
\end{tabular}

Sumber: Hasil olahan peneliti, 2019

Berdasarkan hasil persepsi pengunjung terhadap sarana prasarana, maka 380 pengunjung mempersepsikan keamananan di Pantai Suwuk baik. Tidak pernah ada laporan kehilangan maupun pencopetan selama ini. Hal ini menunjukkan masyarakat mencitrakan keamananan di Pantai Suwuk adalah jauh dari tindak kriminal. Untuk panorama keindahan termasuk cukup, karena setiap tahun masih banyak pengunjung yang ingin berwisata ke pantai Suwuk, apalagi dilengkapi dengan fasilitas tempat bermain yang lumayan ramai sebagai daya tarik anak-anak untuk bermain. Selain itu tersedianya sarana prasarana seperti toilet sudah cukup baik \& terjaga kebersihannya. Di lokasi sekitar pantai Suwuk kondisi kebersihan lingkungan dan pngelolaan sampah memang kurang terjaga kebersihannya, karena kurang dikelola dengan baik oleh manajemen.

\section{KESIMPULAN DAN SARAN}

Dari uraian-uraian diatas, maka dapat disimpulkan bahwa masih banyak para wisatawan yang berminat untuk berkunjung ke pantai Suwuk, karena dari hasil penelitian menunjukkan rata-rata pengeluaran wisatawan dalam satu kali kunjungan sebesar Rp. 161.842,- untuk setiap kali kunjungan. Selain itu pantai Suwuk memiliki dampak ekonomi yang cukup besar untuk masyarakat disekitar, karena memiliki nilai Multiplier lebih dari 1. Hail penelitian menunjukkan, nilai income multiplier terendah adalah nilai income multiplier type 1, yang artinya bahwa pendapatan dari unit usaha sebagai akibat dari adanya pengeluaran wisatawan masih belum maksimal.Oleh karena itu sebaiknya pemerintah mampu mendorong masyarakat sekitar terlibat dam lebih kreatif dalam mengelola pantai.

Adapun saran peneliti pada obyek wisata pantai Suwuk antara lain: kerja sama antara pemerintah, masyarakat area pantai, pengunjung dan investor sangat di perlukan untuk bersama-sama andil dalam mengembangkan pantai Suwuk menjadi pantai yang banyak diminati pengunjung dan memiliki value added yang tinggi. Misal dengan menambah wahana-wahana permainan untuk anakanak maupun dewasa yang menantang, fasilitas sarana dan prasarana lebih lengkap serta terjamin kebersihannya, sehingga wisatawan merasa betah dan nyaman untuk berkunjung kembali karena mendapatkan kepuasan selama berlibur di pantai Suwuk. Agar pengunjung tertib, sebaiknya pintu masuk ke lokasi pantai Suwuk dipusatkan pada pintu gerbang utama saja. Sedangkan untuk area parkir bisa bekerja sama dengan penduduk setempat dengan cara rolling/dijadwalkan.

Meskipun pada bulan Juli 2018 terjadi gelombang pasang tinggi, ternyata minat masyarakat untuk mengunjungi pantai Suwuk tergolong tinggi, jika dilihat dari angka kunjungan. Namun jika pihak manajemen tidak melakukan perbaikan dan pengembangan, maka besar kemungkinan pengunjung akan meninggalkan pantai suwuk untuk berwisata ke pantai lain di wilayah Kebumen yang fasilitasnya semakin baik.

\section{E. DAFTAR PUSTAKA}

Agustina VS. 2009. Analisis persepsi dan preferensi pengunjung serta dampak ekonomi kegiatan wisata Gunung Salak Endah [skripsi]. Bogor (ID): Institut Pertanian Bogor.

Anggraeni AA. 2013. Analisis dampak ekonomi wisata bahari terhadap pendapatan masyarakat di Pulau Untung. Jurnal Online Institut Teknologi Nasional. 20(10):1-8.

Ariyanti, Desi.2014. Pengaruh Sektor Pariwisata Terhadap perekonomian dan Keruangan Kota Bukittinngi Pendekatan analisis Input Output. Jurnal Wilayah Dan Lingkungan Vol 2 No 3. 
Bukittinggi

Fauzi A. 2006. Ekonomi Sumberdaya Alam dan Lingkungan: Teori dan Aplikasi.Jakarta (ID): Gramedia.

Ihsan, Muhamad.2017. Multiplier Effect Industri Priwisata Candi Muara Takus terhadap perekonomian Masyarakat di kecamatan XII OtokamparKabupaten Kampar 689. JOM Fekon Vol 4 No 1. Pekanbaru

Iqbal M. 2007. Analisis peran pemangku kepentingan dan implementasinya dalam masyarakat pembangunan pertanian. Jurnal Litbang Pertanian. 26(3):89-99.

Irianto. 2011. Dampak pariwisata terhadap kehidupan sosial dan ekonomi masyarakat di Gili Trawangan Kecamatan Pemenang Kabupaten Lombok Utara. Jurnal Bisnis dan Kewirausahaan. 7(3):188-196.

Ismayanti. 2010. Pengantar Pariwisata. PT Grasindo. Jakarta.

Kebumen Dalam Angka, BPS 2013-2017

Kusumedi P, Rizal A. 2010. Analisis stakeholder dan kebijakan pembangunan KPH model maros di Propinsi Sulawesi Selatan. Jurnal Analisis Kebijakan Kehutanan. 7(3):179-193.

Leri IAA. 2011. Dampak pengeluaran wisatawan terhadap perkembangan sektor ekonomi di Provinsi Bali [tesis]. Denpasar (ID): Universitas Udayana Denpasar.

Marine Ecotourism for Atlantic Area. 2001. Planning for marine ecotourism in the EU Atlantic Area. University vof the West of England, Bristol.

Pemerintah Desa Tambakmulyo. 2016. Data Kependudukan Desa Tambakmulyo

Riduwan. 2010. Skala Pengukuran Variabel-variabel Penelitian. Alfabeta. Bandung.

Siregar R. 2012. Analisis kelembagaan non-pasar (non-market) dalam efisiensi alokasi sumberdaya perikanan (studi kasus: Pelabuhanratu, Kabupaten Sukabumi) [skripsi]. Bogor (ID): Institut Pertanian Bogor.

Sri, Subiyanti, 2015. Pengukukuran kontribusi terhadap nilai ekonomi obyek wisata kawasan rawapening kabupaten rawapening dengan pendekatan muliplier effect. Proceding seminar nasional UMS. Surakarta.

Undang-undang No 9 Pasal 1 Tahun 1990 Tentang Kepariwisataan. Undang-undang No 10 Tahun 2009 Tentang Kepariwisataan.

UU No 9 Tahun 2009 Tentang Kepariwisataan

Wan Chai. 2009. Introduction to Tourism. Hongkong: Wu Chung House

Wijayanti P. 2009. Analisis ekonomi dan kebijakan pengelolaan wisata alam berbasis masyarakat lokal di Kabupaten Administrasi Kepulauan Seribu Provinsi DKI Jakarta [tesis]. Bogor (ID): Institut Pertanian Bogor. 